\title{
Large tundra methane burst during onset of freezing
}

Mastepanov, Mikhail; Sigsgaard, Charlotte; Dlugokencky, Edward J.; Houwelling, Sander; Ström, Lena; Tamstorf, Mikkel Peter; Christensen, Torben R.

Published in:

Nature

DOI:

10.1038/nature07464

Publication date:

2008

Document version

Publisher's PDF, also known as Version of record

Citation for published version (APA):

Mastepanov, M., Sigsgaard, C., Dlugokencky, E. J., Houwelling, S., Ström, L., Tamstorf, M. P., \& Christensen, T. R. (2008). Large tundra methane burst during onset of freezing. Nature, 456, 628-631.

https://doi.org/10.1038/nature07464 


\title{
Large tundra methane burst during onset of freezing
}

\author{
Mikhail Mastepanov ${ }^{1}$, Charlotte Sigsgaard ${ }^{2}$, Edward J. Dlugokencky ${ }^{3}$, Sander Houweling ${ }^{4,5}$, Lena Ström ${ }^{1}$, \\ Mikkel P. Tamstorf ${ }^{6} \&$ Torben R. Christensen ${ }^{1}$
}

Terrestrial wetland emissions are the largest single source of the greenhouse gas methane ${ }^{1}$. Northern high-latitude wetlands contribute significantly to the overall methane emissions from wetlands, but the relative source distribution between tropical and high-latitude wetlands remains uncertain ${ }^{2,3}$. As a result, not all the observed spatial and seasonal patterns of atmospheric methane concentrations can be satisfactorily explained, particularly for high northern latitudes. For example, a late-autumn shoulder is consistently observed in the seasonal cycles of atmospheric methane at high-latitude sites ${ }^{4}$, but the sources responsible for these increased methane concentrations remain uncertain. Here we report a data set that extends hourly methane flux measurements from a high Arctic setting into the late autumn and early winter, during the onset of soil freezing. We find that emissions fall to a low steady level after the growing season but then increase significantly during the freeze-in period. The integral of emissions during the freeze-in period is approximately equal to the amount of methane emitted during the entire summer season. Three-dimensional atmospheric chemistry and transport model simulations of global atmospheric methane concentrations indicate that the observed early winter emission burst improves the agreement between the simulated seasonal cycle and atmospheric data from latitudes north of $60^{\circ} \mathrm{N}$. Our findings suggest that permafrost-associated freeze-in bursts of methane emissions from tundra regions could be an important and so far unrecognized component of the seasonal distribution of methane emissions from high latitudes.

Methane emissions from permafrost dominated tundra regions are well documented ${ }^{5-7}$ and also recognized as considerable contributors to the dynamics of high-latitude atmospheric methane concentrations $^{8,9}$. The scale and dynamics of growing-season methane emissions from tundra settings have been documented mostly through flux measurements made with low time resolution using manual chambers ${ }^{5,6,10}$ together with some at higher time resolution taken only during the growing season ${ }^{7,11,12}$. Here we report a data set that extends hourly $\mathrm{CH}_{4}$ flux measurements from a high Arctic setting into the frozen season. The measurement site is located in Zackenberg Valley, northeast Greenland, $74.30^{\circ} \mathrm{N} 21.00^{\circ} \mathrm{W}$. Six automated chambers provided flux measurements once per hour, in a typical fen area dominated by graminoids Eriophorum scheuchzeri, Dupontia psilosantha and Arctagrostis latifolia. Methane concentration in the chambers was measured by a laser off-axis integratedcavity output spectroscopy analyser (Fast Methane Analyser, Los Gatos Research). The instrument sensitivity is better than 10 p.p.b.; time resolution of the primary concentration data is $1 \mathrm{~s}$.

As part of the field season of the 2007 International Polar Year, the Zackenberg research station was kept open two months longer than normal. This gave us a chance to observe autumn and early-winter fluxes, which showed some surprisingly high emissions (Fig. 1;
Supplementary Table 1). This very high and variable flux happened when the active layer was gradually freezing, so $\mathrm{CH}_{4}$ that had accumulated in this layer was probably squeezed out through the frost action. This feature has not been observed in studies at lower latitudes, possibly because the permafrost bottom is necessary to prevent $\mathrm{CH}_{4}$ from diffusing downwards. The autumn fluxes varied greatly over small distances (chambers were less than $1 \mathrm{~m}$ apart), probably because peat and vegetation structure provided pathways for emission to the atmosphere. A late-autumn increase in methane emissions was observed in one of the early tundra flux studies ${ }^{13}$, but it lacked the time resolution needed to quantify the relative importance for the annual flux budget.

The observed growing season emission dynamics are comparable to earlier work at the same $e^{6,7}$ and at similar tundra sites ${ }^{12}$. Integrated summer season emissions, roughly $4.5 \mathrm{~g} \mathrm{CH}_{4} \mathrm{~m}^{-2}$ for the season, also match well with previous estimates for the same climatic and ecosystem setting ${ }^{6,7}$.

Emissions decreased during September until they reached the presumed low winter emission level (Fig. 1). However, at the onset of soil freeze-in, a substantial increase in emissions was observed and was sustained for several weeks, corresponding to the time required for a complete freeze-in of the entire soil and root zone profile. Freeze-in emissions were much more variable than summer emissions. Peak emissions during the freeze-in period in individual chambers reached levels of $112.5 \mathrm{mgCH}_{4} \mathrm{~m}^{-2} \mathrm{~h}^{-1}$, which to our knowledge are the highest rates reported from tundra ecosystems (excluding hotspot emissions from thermokarst lakes ${ }^{14}$ ), and they appear at a time when previous assumptions would put tundra emissions at a negligible level (see Supplementary Information for further discussion).

Earlier studies have indicated the possibility of a spring burst from trapped methane during the winter ${ }^{15,16}$. We have early-season flux data from Zackenberg for 2006 (M. Mastepanov et al., manuscript in preparation) showing that spring emissions amounted to less than $2 \%$ of summer emissions (Fig. 1 insert; Supplementary Table 2), with summer emissions being very similar for 2006 and 2007 (Supplementary Tables 1 and 2). Emissions of methane during spring from this type of tundra environment are therefore not considered as a major contributor to annual methane emissions.

To investigate the potential importance of the observed methane emissions during freezing of the permafrost surface layer at large scales, we carried out model simulations of atmospheric transport and compared them with observations. Model-simulated methane concentrations were sampled at the times and locations when measurements were taken at selected background monitoring sites of the NOAA Earth System Research Laboratory's cooperative air sampling network ${ }^{4}$. Average seasonal cycles were constructed from air samples collected over the 4-year simulation period. Furthermore, background sites were averaged into two latitudinal bands: $25-55^{\circ} \mathrm{N}$ 


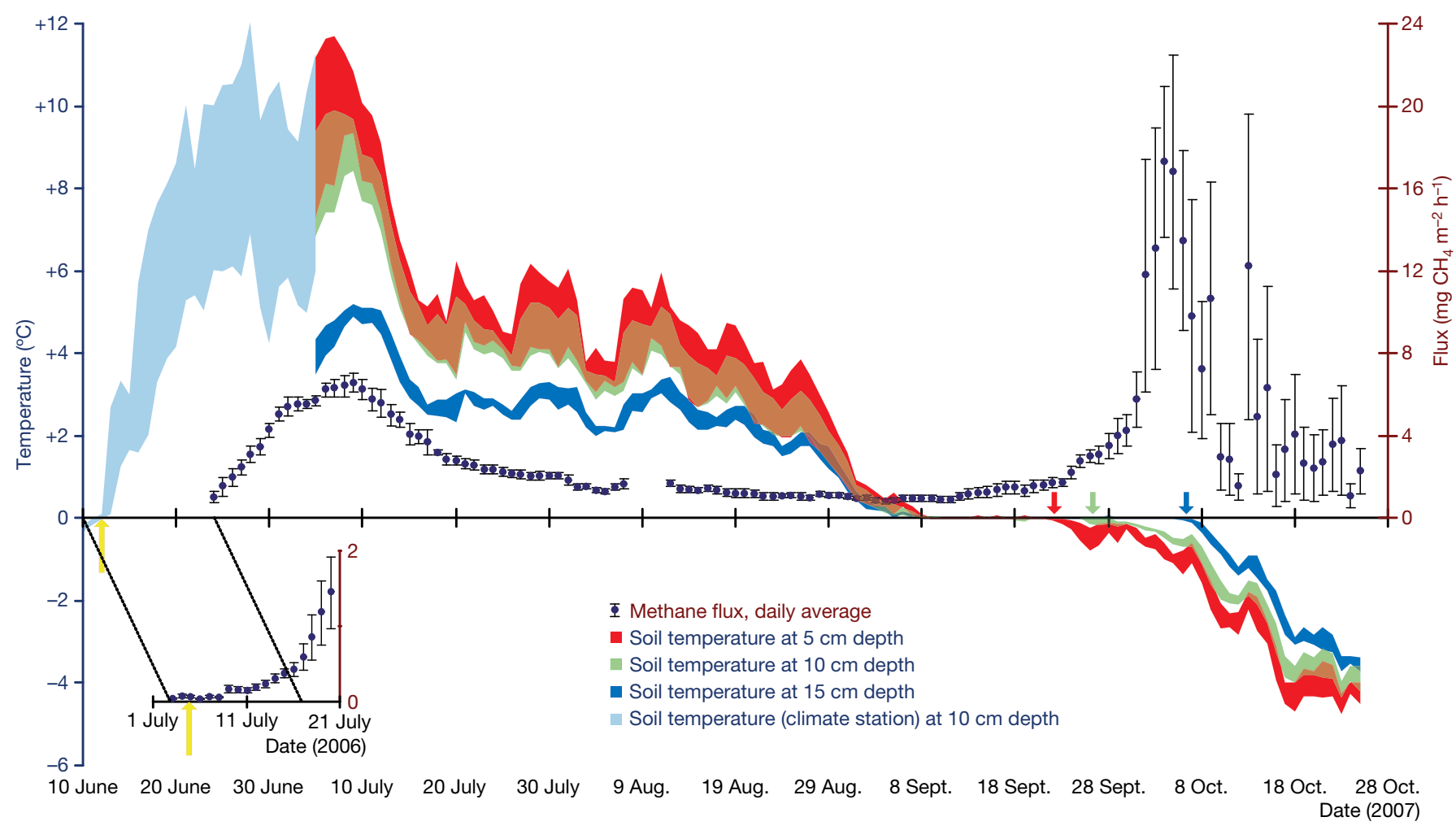

Figure 1 | Full-season methane emission and soil temperature. Soil temperatures at three depths shown as a coloured area between daily minimum and daily maximum values $(5,10$ and $15 \mathrm{~cm}$ depth as red, green and blue). The arrows of the same colour show the date of freezing of each horizon. Soil temperatures from the nearby climate station (light blue) are shown for the period when on-site data are lacking. Site-average fluxes are shown as daily mean values averaged over six individual chambers. The error

and $55-85^{\circ} \mathrm{N}$ (see Methods for a list of sites and where to access the $\mathrm{CH}_{4}$ data). The averages represent 30-day running means of all samples (either modelled or measured), calculated in 5-day intervals.

There is a very reasonable agreement between the reference emission scenario (SC1) and the measurements (Fig. 2). At mid latitudes of the Northern Hemisphere, both model scenarios nicely reproduce the seasonal amplitude, although the phase lags the measurements by about a month in the second part of the year. At high northern latitudes the differences between model and measurements are more

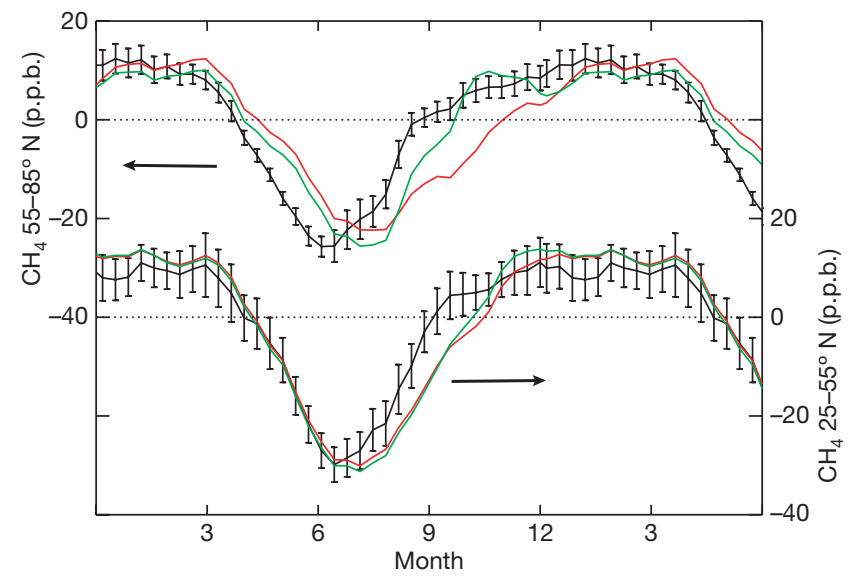

Figure 2 Comparison of measured and model-simulated latitudinally averaged seasonal cycles of methane. Black, measurements with 2 sigma uncertainty intervals; red, the model simulation using the reference scenario; green, the model simulation including a representation of additional emissions from freezing permafrost (see text). bars show standard error of mean between the chambers. The lower inserted panel shows early-season emission in 2006 during the corresponding period relative to the date of snowmelt in 2007 (yellow arrows indicate date of snowmelt in the two years). The onset of the second emission peak coincides with freezing of the upper horizon and continues to reach a maximum when soil freezes down to $-15 \mathrm{~cm}$.

pronounced, highlighting a deficiency of the reference model in simulating the timing of the concentration increase from summer to winter. Interestingly, the largest deviations occur in October when the unrepresented emissions from permafrost are highest. The difference between the two model simulations confirms that the influence of the simulated permafrost emissions is considerable and does improve the simulated seasonal cycle. Significant differences remain between model SC2 and the measurements, but it should be kept in mind that the underlying parameterization is only a preliminary extrapolation of the actual flux measurements. Therefore, once additional information on permafrost freeze-in emissions become available, confirmation of our model results is needed on the basis of a more sophisticated emission parameterization. Nevertheless, these results show that $\mathrm{CH}_{4}$ emissions from the freezing active layer in permafrost areas may be an important missing process that limits model performance at high northern latitudes.

We also investigated whether there has been a change in the shape of the seasonal cycle in recent years by comparing observed seasonal cycles for the periods 1992-95 and 2002-05. The results (Supplementary Fig. 3) demonstrate that both seasonal cycles (25$55^{\circ} \mathrm{N}$ and $55-85^{\circ} \mathrm{N}$ ) were remarkably constant over these periods, indicating that the signature of permafrost emissions in the observed seasonal cycle is not a recent phenomenon.

The flux measurements and atmospheric transport model results presented here are likely to be of a general nature, as there is nothing unique or artificial about this study site. It is situated in one of the most pristine environments in the world (the National Park of northeast Greenland) and there is no reason why such a physical mechanism should not happen everywhere that there are similar ecosystems. This study benefited from the unique opportunity through the International Polar Year effort to keep the Zackenberg 
station open for longer than usual, and thus to observe a phenomenon that has most likely been missed in other measurements around the circumpolar north because of the difficulties of maintaining flux measurements into the frozen season at remote high-emitting wet tundra sites. If the fluxes measured at Zackenberg are applied to all of $0.88 \times 10^{12} \mathrm{~m}^{2}$ of wet meadow tundra ${ }^{17}$ (disregarding possible similar emissions from mesic tundra which covers even greater areas), it will amount to a pulse of $\sim 4 \mathrm{Tg} \mathrm{CH}_{4}$ from the highest latitudes at what was previously thought to be an inactive time of year in terrestrial ecosystems. This is in agreement with a corresponding estimate based on the three-dimensional modelling which amounts to 3.9 $\mathrm{Tg} \mathrm{CH}_{4}$ (see Methods). This does not greatly increase emission estimates from high northern latitudes, but it revises our view of the seasonal distribution of known emissions.

\section{METHODS SUMMARY}

Methane emissions were measured by an automatic chamber method; flux was calculated from the increase in the chamber $\mathrm{CH}_{4}$ concentration, corrected by air temperature and pressure. Erroneous measurements (for instance, during strong southerly winds that tend to cause improper closing of the chambers) were filtered out and no artificial corrections or gap filling were applied.

Global methane concentrations were simulated using an atmospheric chemistry and transport model, which includes a dedicated representation of the methane cycle. Calculations were performed with and without a parameterization of methane emissions from freezing permafrost. Simulated concentrations were compared with high precision methane measurements representative of the background conditions at mid to high northern latitudes.

Full Methods and any associated references are available in the online version of the paper at www.nature.com/nature.

\section{Received 25 April; accepted 18 September 2008.}

1. Mikaloff Fletcher, S. E., Tans, P. P., Bruhwiler, L. M., Miller, J. B. \& Heimann, M. CH sources estimated from atmospheric observations of $\mathrm{CH}_{4}$ and its ${ }^{13} \mathrm{C} /{ }^{12} \mathrm{C}$ isotopic ratios: 1. Inverse modeling of source processes. Glob. Biogeochem. Cycles 18, GB4004 (2004).

2. Dlugokencky, E. J. et al. Atmospheric methane levels off: Temporary pause or a new steady-state? Geophys. Res. Lett. 30, 1992 (2003)

3. Miller, J. B. et al. Airborne measurements indicate large methane emissions from the eastern Amazon basin. Geophys. Res. Lett. 34, L10809 (2007).

4. Dlugokencky, E. J., Steele, L. P., Lang, P. M. \& Masarie, K. A. The growth rate and distribution of atmospheric methane. J. Geophys. Res. 99, 17021-17043 (1994).

5. Reeburgh, W. S. et al. A $\mathrm{CH}_{4}$ emission estimate for the Kuparuk River basin, Alaska. J. Geophys. Res. 103, 29005-29013 (1998).

6. Christensen, T. R. et al. Trace gas exchange in a high-arctic valley 1. Variations in $\mathrm{CO}_{2}$ and $\mathrm{CH}_{4}$ flux between tundra vegetation types. Glob. Biogeochem. Cycles 14, 701-713 (2000).
7. Friborg, T., Christensen, T. R., Hansen, B. U., Nordstroem, C. \& Soegaard, H. Trace gas exchange in a high-arctic valley 2. Landscape $\mathrm{CH}_{4}$ fluxes measured and modeled using eddy correlation data. Glob. Biogeochem. Cycles 14, 715-723 (2000).

8. Gedney, N., Cox, P. M. \& Huntingford, C. Climate feedback from wetland methane emissions. Geophys. Res. Lett. 31, L20503 (2004).

9. Bousquet, P. et al. Contribution of anthropogenic and natural sources to atmospheric methane variability. Nature 443, 439-443 (2006).

10. Christensen, T. R. Methane emission from Arctic tundra. Biogeochemistry 21, 117-139 (1993).

11. Fan, S. M. et al. Micrometeorological measurements of $\mathrm{CH}_{4}$ and $\mathrm{CO}_{2}$ exchange between the atmosphere and subarctic tundra. J. Geophys. Res. 97, 16627-16644 (1992).

12. Corradi, C., Kolle, O., Walter, K., Zimov, S. A. \& Schulze, E.-D. Carbon dioxide and methane exchange of a north-east Siberian tussock tundra. Glob. Change Biol. 11, 1910-1925 (2005).

13. Whalen, S. C. \& Reeburgh, W. S. A methane flux time series for tundra environments. Glob. Biogeochem. Cycles 2, 399-409 (1988).

14. Walter, K. M., Zimov, S. A., Chanton, J. P., Verbyla, D. \& Chapin, F. S. III. Methane bubbling from Siberian thaw lakes as a positive feedback to climate warming. Nature 443, 71-75 (2006).

15. Hargreaves, K. J., Fowler, D., Pitcairn, C. E. R. \& Aurela, M. Annual methane emission from Finnish mires estimated from eddy covariance campaign measurements. Theor. Appl. Climatol. 70, 203-213 (2001).

16. Tokida, T. et al. Episodic release of methane bubbles from peatland during spring thaw. Chemosphere 70, 165-171 (2007).

17. Bliss, L. C. \& Matveyeva, N. V. in Arctic Ecosystems in a Changing Climate: An Ecophysiological Perspective (eds Chapin, F. S. III, Jefferies, R. L., Reynolds, J. F., Shaver, G. R. \& Svoboda, J.) 59-89 (Academic, 1992).

Supplementary Information is linked to the online version of the paper at www.nature.com/nature.

Acknowledgements This work was carried out under the auspices of the GeoBasis programme and part of the Zackenberg Ecological Research Operations funded by the Danish Ministry of the Environment and the ISICaB project funded by the Commission for Scientific Research in Greenland (KVUG). ASIAQ-Greenland Survey provided climate data. The work was also supported by the Swedish Research Councils VR and FORMAS. We thank P. Bergamachi (JRC) and J.-F. Meirink (KNMI) for providing the TM5 model setup. T. Tagesson helped with the field work in Zackenberg. We are grateful for comments on earlier versions of this manuscript from A. Lindroth and B. Christensen.

Author Contributions T.R.C., M.P.T., M.M., C.S. and L.S. designed the field research; M.M. designed, constructed and set up the automatic measurement system in Zackenberg; C.S. operated the system and performed manual measurements; M.M. performed data analysis; E.D. and S.H. provided atmospheric $\mathrm{CH}_{4}$ data and designed and ran the atmospheric transport model experiments; T.R.C., M.M., S.H. and E.D. drafted the manuscript.

Author Information Reprints and permissions information is available at www.nature.com/reprints. Correspondence and requests for materials should be addressed to T.R.C. (Torben.Christensen@nateko.lu.se). 


\section{METHODS}

Zackenberg site description. The Zackenberg Valley is situated at $74^{\circ} 30^{\prime} \mathrm{N}$, $21^{\circ} 00^{\prime} \mathrm{W}$ in the National Park of northeast Greenland. A research station (Zackenberg Research Station) was established in 1997 and offers basic logistical facilities (an airstrip, laboratories, satellite-based communication systems and so forth) necessary for carrying out efficient research. The site has a short record of meteorological observations, and 1996 was the first full year when basic meteorological variables were registered continuously. Mean annual temperature in the first 10 -year period of the station ranged from $-8.5^{\circ} \mathrm{C}$ to $-10.1^{\circ} \mathrm{C}$ with July as the warmest month (mean monthly air temperature of $5.8^{\circ} \mathrm{C}$ ) and February as the coldest month (mean monthly air temperature of $-22.4^{\circ} \mathrm{C}$ ). The average frost-free period during these 10 years was 35 days, lasting from mid July to late August. In Daneborg, situated on the outer coast $22 \mathrm{~km}$ southeast of Zackenberg and with a longer period of meteorological measurements, the mean annual temperature for the period $1960-90$ was $-10.3^{\circ} \mathrm{C}$. The warmest month, July, had a mean of $3.8^{\circ} \mathrm{C}$ and February, the coldest month, had a monthly mean of $-17.6^{\circ} \mathrm{C}$. The valley is dominated by minerotrophic sedgegrass-rich fens mixed with elevated areas of dwarf shrub heaths with Cassiope tetragona and Salix arctica as dominant species. A slightly sloping fen area is the main study area here. The peat layer in the fen is $20-30 \mathrm{~cm}$ thick, typical of high arctic fen ecosystems ${ }^{18}$. Onset of peat accumulation has been ${ }^{14} \mathrm{C}$-dated to $\mathrm{AD}$ 1290-1390 in a neighbouring fen area, and the surrounding Little Ice Age nival fans and nivation basins primarily contain organic material deposited from $\mathrm{AD}$ 1420 to $1500-1580^{19}$.

The active layer depth specifically on the measurement site reached $50-56 \mathrm{~cm}$ (near different chambers) before soil freezing in 2007. Despite the low temperatures, the snow cover was mosaic until 20 October, and then was no more than $3 \mathrm{~cm}$ deep until the first snowstorm on 26 October.

A large body of background information from the Zackenberg Research Station has recently been summarized in a book volume celebrating the first 10 years of activities at the research station ${ }^{18}$.

Methane flux measurements. Automatic chambers were deployed in August 2005 and the first seasonal data set was obtained in 2006 ( 3 July to 26 August). In 2007 an extended season was carried out (26 June to 25 October). Six chambers have been aligned in a row from the periphery of the fen towards its central part. The distance between the chambers is $30-80 \mathrm{~cm}$. The chambers are made of Plexiglas with aluminium corners. Each chamber is $60 \times 60 \mathrm{~cm}$ and about $30 \mathrm{~cm}$ height (depending on microtopography). The chamber lid stays open for $55 \mathrm{~min}$ per hour and closes for five minutes for the measurements. Air is mixed in a closed chamber by a fan; the same fan ventilates a chamber when it is open. Air from the chamber passes through $30 \mathrm{~m}$ of tubing (internal diameter $4 \mathrm{~mm}$ ) to the analytical box and after the non-destructive analysis it goes back to the chamber. The analytical box contains a methane analyser (Fast Methane Analyser, Los Gatos Research), $\mathrm{CO}_{2}$ analyser (SBA-4, PP Systems) and solenoid valves. The concentration data are collected at $1 \mathrm{~Hz}$ rate; data acquisition starts three minutes before a chamber closes, continues for five minutes while it is closed, and then two minutes after the chamber opens, so the full cycle of six chambers takes one hour.

Although we did not make direct measurements of soil temperature and humidity inside the chambers, to avoid extra disturbance, the visual control does not give any evidence of the construction affecting the temperature and water regime inside the chambers. Visible water table and the snow level (during the snowfall and snowmelt) is the same inside and outside the chambers.
The $\mathrm{CH}_{4}$ fluxes are calculated from the slope of concentration change in the closed chamber; if the increase was not linear during five minutes of closure, the most linear part of this time is arbitrarily chosen. The air temperature and pressure for flux calculations are obtained from Zackenberg micrometeorological station located about $1 \mathrm{~km}$ from the site. We made additional measurements of water table level, active layer depth, PAR, soil temperature and humidity next to the chambers.

Atmospheric $\mathrm{CH}_{4}$ measurements and chemical transport model. Atmospheric $\mathrm{CH}_{4}$ measurements are from weekly samples collected at sites in the NOAA Earth System Research Laboratory's cooperative global air sampling network ${ }^{4}$. We determined methane dry-air mole fractions by gas chromatography with flame ionization detection against the $\mathrm{WMO} \mathrm{CH}_{4}$ mole fraction standard scale. Over the period of this study, repeatability of the measurements $(1 \sigma)$ was $\sim 2$ p.p.b. Latitudinal averages contained the following sites: $25-55^{\circ} \mathrm{N}$ contained 'mid', 'bme', 'bmw', 'uta', 'mhd', 'ask', 'nwr', 'pta', 'azr', 'izo', 'pocn30' and 'pocn25', and $55-85^{\circ} \mathrm{N}$ contained 'alt', 'shm', 'brw', 'ice', 'zep', 'stm', 'cba' and 'sum' (see www.esrl.noaa.gov/gmd/ccgg/flask.html for a list of site codes and ftp:// $\mathrm{ftp.cmdl.noaa.gov/ccg/ch} 4 /$ flask/event for access to data).

We made atmospheric transport model calculations using the TM5 model ${ }^{20}$ for the period 2002-05, at a spatial resolution of $6^{\circ} \times 4^{\circ}$ and 25 vertical sigmapressure levels. Two scenarios of methane sources and sinks were applied: a reference scenario (SC1) and a scenario including emissions from permafrost freeze-in (SC2). The methane sources and sinks of SC1 correspond with the a priori assumptions that were used in the inverse modelling calculations of ref. 21, with the exception of wetlands. Wetland emissions were taken from ref. 22. and rescaled to a global total of $175 \mathrm{Tg} \mathrm{CH}_{4} \mathrm{yr}^{-1}$ and high-latitude $\left(50-90^{\circ} \mathrm{N}\right)$ emissions of $20 \mathrm{Tg} \mathrm{CH}_{4} \mathrm{yr}^{-1}$. SC2 is the same as $\mathrm{SC} 1$ except for additional emissions from freezing permafrost. For lack of any detailed information on this process, we followed a highly simplified procedure, assuming that emission started when the diurnal mean temperature dropped below $-2{ }^{\circ} \mathrm{C}$ and continued for a period of 1 month. This process was only active in those model grid boxes that were classified as continuous or discontinuous permafrost according to the CAPS circumpolar permafrost map ${ }^{23}$. The annual emission of freezing permafrost was assumed to be the same as the (summer time) wetland emission in each model grid box for which the process is active. This procedure introduces an additional source of $3.9 \mathrm{Tg} \mathrm{CH}_{4} \mathrm{yr}^{-1}$, which moves from north to south during autumn and reaches maximum global emissions in October.

18. Meltofte, H., Christensen, T. R., Elberling, B., Forchhammer, M. C. \& Rasch, M. (eds) High-Arctic Ecosystem Dynamics in a Changing Climate. Advances in Ecological Research Vol. 40 (Elsevier, 2008)

19. Christiansen, H. H. et al. Holocene environmental reconstruction from deltaic deposits in northeast Greenland. J. Quat. Sci. 17, 145-160 (2002).

20. Krol, M. C. et al. The two-way nested global chemistry-transport zoom model TM5: algorithm and applications. Atmos. Chem. Phys. 5, 417-432 (2005).

21. Bergamaschi, P. et al. Satellite chartography of atmospheric methane from SCIAMACHY on board ENVISAT. 2. Evaluation based on inverse model simulations. J. Geophys. Res. 112, D02304 (2007).

22. Walter, B. P., Heimann, M. \& Matthews, E. Modeling modern methane emissions from natural wetlands. 2. Interannual variations 1982-1993. J. Geophys. Res. 106, 34207-34217 (2001).

23. Brown, J., Ferrians, O. J. Jr, Heginbottom, J. A. \& Melnikov, E. S. Circum-arctic Map of Permafrost and Ground-Ice Conditions. USGS Circum-Pacific Map Series CP-45 (scale 1:10,000 000) (US Geological Survey, 1997). 